\title{
Atratividade das principais nações exportadoras de compensado ao investimento privado
}

\author{
Peterson Silva de Sousa ${ }^{1}$, Rommel Noce ${ }^{1 \star}$, Juliana Mendes de Oliveira ${ }^{1}$ \\ ${ }^{1}$ Instituto de Biodiversidade e Florestas (IBEF), Universidade Federal do Oeste do Pará (UFOPA), Santarém, Pará, Brasil.
}

\begin{abstract}
RESUMO O presente trabalho objetivou analisar a relação risco-retorno das principais nações exportadoras de compensado no período de 2003 a 2013. Admitiu-se a taxa geométrica de crescimento (TGC) como indicativo de retorno e o coeficiente de variação $(\mathrm{CV})$ como indicativo de risco. Especificamente estimou-se o risco e o retorno das seguintes nações: Brasil, China, Estados Unidos, Malásia, Rússia e Indonésia, identificadas como as principais nações exportadoras de compensado. Brasil e EUA destacam-se como mercados atrativos ao investidor tradicional. Enquanto que os mercados de Malásia e Indonésia mostraram-se menos atrativos ao investimento privado, tendendo a sofrer queda de investimentos futuramente. O cenário contemplado na Rússia e China apresentou-se atrativo ao investidor agressivo, com altas taxas de risco associadas a retornos elevados. O mercado internacional de compensado é altamente concentrado, o que pode comprometer a alocação dos investimentos privados em função da sua organização em oligopólio.
\end{abstract}

Palavras-chave: comércio internacional, economia florestal, risco e retorno.

\section{Attractiveness of the major exporting nations of plywood to private investment}

\begin{abstract}
The present work aimed to analyze the risk-return in the period of 2003 to 2013. It was admitted the geometric growth rate (TGC) as indicative of return and the variation coefficient (CV) as indicative of the risks. Specifically, it was estimated the risk and return of the following Nations: Brazil, China, United States, Malaysia, Russia and Indonesia, identified as the major exporting nations of plywood. It was concluded that Brazil and the United States stands out as markets attractive to the traditional investor. While Malaysia and Indonesia markets were less attractive to private investment, tending to suffer decrease in future investment. The scenario included in Russia and China appeared attractive to the aggressive investor, with high rates of risk associated with high returns. The international market of plywood is highly concentrated, which can affect the allocation of private investment because of its organization's in oligopoly.
\end{abstract}

Keywords: NIR; international trade, forest economy, risk and return.

\section{Introdução}

O Brasil apresenta uma indústria de base florestal que ao longo dos anos vem ampliando sua participação no mercado internacional. O potencial produtivo aumenta a cada ano, principalmente em função dos investimentos em tecnologia, aumento dos ativos florestais e busca de formas mais adequados de produção que atendam a exigências de qualidade no mercado (SOUZA et al., 2014)
Os painéis de madeira, especificamente o compensado, vêm ganhando destaque no setor florestal e na economia brasileira na última década. Destacando-se para tal o crescimento do seu potencial produtivo (EISFELD; BERGER, 2012).

O risco fundamentalmente pode ser entendido como a possibilidade de prejuízo financeiro. Referindo-se à variabilidade do retorno associado a certo ativo, no sentindo formal. Assim, quanto menor a variabilidade, menor será o risco associado a um determinado ativo (GITMAN, 2010). 
Segundo Silva (2007), a análise da dinâmica da atividade florestal demonstra que o setor exige altos investimentos nos primeiros anos. Oferecendo, em curto prazo, baixas taxas de retorno inicial devido ao lento amadurecimento da floresta. Dessa forma, tende a permitir o retorno do capital em longo prazo. Sendo indispensável avaliar a relação risco-retorno dos produtos florestais, no sentido de contribuir para a percepção da atratividade de capital privado para esse setor.

A concentração industrial é fundamental para a análise estrutural de mercado, variando ao nível teórico da concorrência perfeita ao monopólio. O cenário de competição perfeita apresentaria a oferta de um produto homogêneo, livre entrada e saída de mercado além de elevado número de participantes. Enquanto que no monopólio, existiria unicamente um produtor oferecendo um produto diferenciado e a entrada de novos participantes seria bloqueada (CARVALHO; AGUIAR, 2005).

A concentração industrial elevada intensifica a desigualdade na distribuição do mercado entre os participantes. Dessa forma os atores envolvidos que possuem maiores parcelas, normalmente, terão maior poder de mercado (KUPPER; HASENCLEVER, 2013).

Considerando a estrutura de mercado, uma elevada concentração pode ser indesejável, visto que este cenário favorece a alocação ineficiente de recursos em virtude da redução da competição (FILHO et al., 2013).

Dessa maneira, buscou-se analisar a atratividade do mercado das principais nações exportadoras ao investimento privado. Especificamente buscou-se: estimar a relação risco-retorno do Brasil, China, Estados Unidos, Malásia, Rússia e Indonésia; e verificar a desigualdade no mercado internacional de compensado.
Os dados para realização dos cálculos foram obtidos a partir de relatórios da Food and Agriculture Organization (FAO, 2015), elaborados no período de 2003 a 2013, referentes ao preço médio praticado por Brasil, China, EUA, Indonésia, Malásia e Rússia no mercado internacional de compensado.

Séries históricas de preços foram estruturadas de forma a permitir estimar a Taxa geométrica de crescimento (TGC) e o coeficiente de variação $(\mathrm{CV})$, admitidos como retorno e risco, respectivamente, conforme Santos e Santana (2009) e Barbosa et al. (2014).

Especificamente para estimar a tendência, o tempo atuou como regressor e definiu-se como regressando o evento objeto de análise. Utilizaram-se os softwares E-Views 5.0 e Excel para o tratamento dos dados obtidos.

A taxa geométrica de crescimento é dada pela Equação 1.

$$
\text { TGC } Y=(\operatorname{ant} \log \beta-1)^{\star} 100
$$

Em que: $\mathrm{TGC}=$ taxa geométrica de crescimento; $\beta=$ coeficiente de regressão.

O coeficiente de regressão teve seus valores estimados com o ajuste da equação de tendência (Equação 2), através da série histórica da variável dependente, em dólares por metro cúbico $\left(\mathrm{US} \$ / \mathrm{m}^{3}\right)$.

$$
\log \mathrm{Y}=\mathrm{c}+\beta \mathrm{t}
$$

Em que: $\mathrm{Y}=$ variável; $\mathrm{c}=$ constante de regressão; $\mathrm{t}=$ tempo.

$\mathrm{O}$ risco foi admitido como $\mathrm{CV}$, conforme Barbosa et al. (2014), sendo uma medida aplicável a séries históricas de diferentes distribuições. Obtido pelo quociente entre o desvio padrão e a média dos preços da série histórica, conforme a Equação 3.

\section{Material e Métodos}




$$
\mathrm{CV}=\mathrm{s} / \overline{\mathrm{x}}
$$

(Equação 3)

Em que: $\mathrm{CV}=$ coeficiente de variação; $\mathrm{s}=$ desvio padrão; $\overline{\mathrm{x}}=$ valores médios.

O nível de concentração de um mercado é usado para verificar se existe uma situação de competição perfeita, de um monopólio ou de algo intermediário (competição monopolísticas ou oligopolísticas). Uma forma de medir o nível de concentração de mercado é através do índice de concentração das quatro maiores firmas (EISFELD; BERGER, 2012).

Adotou-se a caracterização do mercado internacional quanto à sua concentração proposta por Gregory (1987), apresentada na Tabela 1.

Tabela 1 - Caracterização do mercado quanto à concentração.

Table 1 - Market characterization for concentration.

\begin{tabular}{cc}
\hline Caracterização & $\begin{array}{c}\text { Participação das 4 maiores } \\
\text { nações exportadoras }\end{array}$ \\
\hline Extremamente concentrado & $\leq 75 \%$ \\
Altamente concentrado & $74 \%$ a $50 \%$ \\
Moderadamente concentrado & $49 \%$ a $25 \%$ \\
Relativamente pouco & $\geq 24 \%$ \\
concentrado &
\end{tabular}

Fonte: Gregory (1987).

Quanto à estrutura do mercado internacional de compensado, considerou-se o proposto por Caves (1982), conforme os critérios observados na Tabela 2.

Tabela 2 - Estrutura de mercado quanto à participação.

Table 2 - Market structure for participation.

\begin{tabular}{cccc}
\hline Estrutura de & \multicolumn{3}{c}{ Participação das nações exportadoras } \\
\cline { 2 - 4 } Mercado & 4 maiores & 8 maiores & 20 maiores \\
\hline Oligopólio I & - & $50 \%$ & $75 \%$ \\
Oligopólio II & - & $33 \%$ & $75 \%$ \\
Indústria não- & - & $<33 \%$ & - \\
concentrada & & & - \\
Indústria & $<10 \%$ & - & \\
competitiva & & & \\
\hline
\end{tabular}

Fonte: Caves (1982)

\section{Resultados e Discussão}

O comportamento do preço do compensado no período de tempo analisado nas principais nações exportadoras mostrou resultados positivos com tendência de crescimento em todos os mercados, variando entre $2,84 \%$ a $7,93 \%$ ao ano.

A atratividade do mercado ao investimento privado mostrou-se diferenciada entre as nações, o que pode ser verificado com a relação risco-retorno. O cenário caracteriza um mercado global atrativo aos investidores de perfis distintos, contemplando tanto o investidor mais agressivo, como o investidor mais tradicional (Figura 1).

O Brasil apresentou a taxa de retorno mais baixa entre as nações com um risco maior que o observado nos EUA. Essa condição mostra que o mercado brasileiro é menos atrativo ao investimento privado do que o americano. Em relação às demais nações, o Brasil destaca-se ao investidor tradicional, devido a sua menor taxa de risco, atraindo dessa forma um investidor com perfil avesso ao risco. Vale ressaltar que ao analisar o cenário de investimentos entre os EUA e Brasil, percebe-se que o investidor se tornaria propenso ao investimento no mercado americano. O que é percebido em função de taxas de riscos inferiores e expectativas de retorno superiores.

Analogicamente, diante da perspectiva de investimento entre o mercado da Rússia e Indonésia, espera-se que o investidor se mostre mais atraído pelo mercado Russo. Enquanto a China seria mais susceptível a obtenção de investimentos privados do que a Malásia por apresentar nível de retorno superior ao mesmo nível de risco.

Verificou-se que a China possui um nível de retorno superior às demais nações. Exceto quando comparada à Rússia, frente a qual apresenta menor taxa de risco. Configurando uma opção de investimento mais atrativa ao investidor tradicional quando comparada a esta nação. 
Os EUA possuem a menor taxa de risco associado entre as nações, além de um retorno próximo de nações com taxas de risco maiores (China, Malásia e Indonésia). Esse cenário torna o mercado americano ideal para a captação de investidores com um perfil tradicional, que não desejam enfrentar muitos riscos e mesmo assim obter retorno.

A Indonésia apresentou a pior relação dentro do grupo de nações analisadas. Apesar de mostrar taxa de retorno dentre as maiores, seu risco é mais elevado, não sendo dessa forma um mercado comparativamente atrativo. Principalmente frente à Rússia e à China, que mostraram níveis de retorno superiores a menores riscos.

A Malásia mostrou-se mais atrativa que a Indonésia, mas em relação à China seu mercado é menos atrativo. Podendo ainda atrair investidores mais agressivos frente aos mercados do Brasil e dos EUA, por supera-los em retorno, porém a taxas mais elevadas de risco. Entretanto, considerar esta tendência pode se tornar errático frente ao mercado russo.

A Rússia apresentou valores altos tanto de risco como retorno. Sendo o mercado que apresentou o maior valor associado a risco e a retorno. Adequada ao perfil de investidor agressivo que procura um mercado com retornos maiores, mas que assume os riscos inerentes a essa decisão.

Os EUA, a China e a Rússia demostraram uma maior atratividade em relação às demais nações pesquisadas. Dessa forma, estas nações teriam maior facilidade na captação de recursos para investimentos na indústria de painéis compensados.

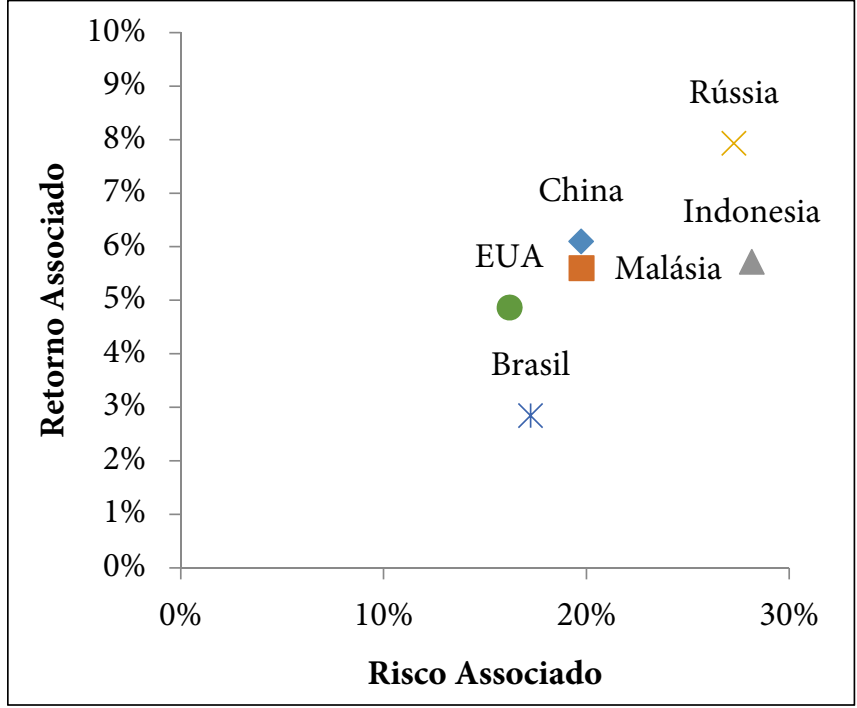

Figura 1. Relação Risco-Retorno das nações exportadoras de compensado de 2003 a 2013.

Figure 1. Risk-return relationship among the Nations from 2003 to 2013.

Verificou-se, ano de 2013, que as nações que apresentaram os maiores retornos associados (Rússia, China, Indonésia e Malásia) também concentraram parte significativa do mercado internacional de compensado. Tais nações responderam por $66,26 \%$ do valor total exportado nesse ano conforme Tabela 3 .

O Brasil é o país do continente sul-americano melhor posicionado no mercado internacional de painéis compensados. Superando nações como EUA e Canadá. O compensado brasileiro representou 2,88\% do valor exportado em 2013, equivalente à US\$ 429.299. Distante da participação da China de 33,64\% do mercado global, correspondendo a US\$ 5.013.615.

O mercado interacional apresentou-se como Altamente Concentrado, conforme proposto por Gregory (1987). Panorama admitido em mercados nos quais as 4 maiores nações totalizam participação entre 74 a 50\%. Especificamente no mercado de painéis compensados as 4 principais nações responderam por $66,26 \%$ do volume total exportado no ano de 2013 (Tabela 4). Segundo Kupfer e Hasenclever (2013) (ESTA CITAÇÃO NÃO ESTÁ NAS REFERÊNCIAS), mercados altamente concentrados apresentam grandes barreiras para a 
entrada de novos concorrentes, permitindo dessa forma que a concentração se perpetue por um longo período.

Tabela 3. Participação percentual das 20 principais nações exportadoras de compensado no ano de 2013.

Table 3. Percentage participation of the 20 major plywood exporters nations in the year 2013.

\begin{tabular}{|c|c|c|c|}
\hline & País & $\begin{array}{c}\text { Valor } \\
(1.000,00 \text { US\$) }\end{array}$ & $\begin{array}{c}\text { Participação } \\
(\%)\end{array}$ \\
\hline 1 & China & 5.013 .615 & 33,64 \\
\hline 2 & Indonésia & 2.176 .212 & 14,60 \\
\hline 3 & Malásia & 1.688 .713 & 11,33 \\
\hline 4 & Rússia & 995.499 & 6,68 \\
\hline 5 & Finlândia & 636.432 & 4,27 \\
\hline 6 & Brasil & 429.229 & 2,88 \\
\hline 7 & USA & 410.038 & 2,75 \\
\hline 8 & Áustria & 276.376 & 1,85 \\
\hline 9 & Alemanha & 271.708 & 1,82 \\
\hline 10 & Chile & 253.603 & 1,70 \\
\hline 11 & Canadá & 213.783 & 1,43 \\
\hline 12 & Letônia & 207.031 & 1,39 \\
\hline 13 & Bélgica & 195.314 & 1,31 \\
\hline 14 & Espanha & 193.615 & 1,30 \\
\hline 15 & Vietnã & 184.713 & 1,24 \\
\hline 16 & França & 166.356 & 1,12 \\
\hline 17 & Itália & 157.787 & 1,06 \\
\hline 18 & Polônia & 155.046 & 1,04 \\
\hline 19 & Romênia & 91.096 & 0,61 \\
\hline 20 & $\begin{array}{c}\text { República } \\
\text { Tcheca }\end{array}$ & 83.050 & 0,56 \\
\hline & TOTAL & 13.799 .216 & 93 \\
\hline
\end{tabular}

Tabela 4. Participação percentual acumulada das principais nações exportadoras de painel compensado no ano de 2013.

Table 4. Accumulated percentage participation of the major exporting Nations of plywood panel in the year 2013.

\begin{tabular}{cc}
\hline Nações Exportadoras & Participação \% em 2013 \\
\hline 4 maiores & $66,26 \%$ \\
8 maiores & $78,02 \%$ \\
20 maiores & $92,60 \%$ \\
\hline
\end{tabular}

A estrutura do mercado internacional de compensado foi admitida como Oligopólio I conforme pressupostos de Caves (1982). O cenário observado no ano de 2013 mostrou as 8 maiores nações detendo participação superior a 50\% em quanto que as 20 principais nações perfaziam valores acima de $75 \%$. O mercado oligopolista se caracteriza pela presença uma pequena quantidade de participantes disputando a hegemonia do mercado ou vários participantes tendo uma empresa liderando o mercado de forma diferenciada, além de apresentar barreiras para a entrada de novos integrantes (MELO; TAVARES, 2009).

\section{Conclusões}

Os EUA destacam-se como mercado mais atrativo ao investidor de perfil tradicional, avesso ao risco. Enquanto a Rússia mostrou potencial para atrair o investidor mais agressivo, propenso ao risco. A China assume uma posição intermediária entre estas opções de investimento.

Malásia, Indonésia e Brasil apresentaram relação risco-retorno coerente, embora não se destaquem em termos de atratividade.

O grau de concentração e a estrutura oligopolizada favorecem a hegemonia das principais nações exportadoras. Intensificando a atratividade dos mercados hegemônicos aos investimentos privados.

\section{Agradecimentos}

À FAPESPA por concessão de bolsa.

\section{Referências}

BARBOSA, H. F.; REGO, L. J. S.; PIERO, M. E.; NOCE, R.; OLIVEIRA, J. M. de ; GAMA, J. R. V. Risk-Return and Diference of ipe wood price in Pará and São Paulo Markets. Cerne, Lavras, v. 20, n. 1, p. 69-72, jan./mar. 2014

CARVALHO, L. H. de; AGUIAR, D. R. D. Concentração de Mercado e Poder de Monopsônio na Indústria Brasileira de Esmagamento de Soja. Revista de Economia e Agronegócio, v.3, n.3, 2005. 
CAVES, R. E. American industry,structure, conduct and performance. Englewood Cliffs: Prentice Hall, 1982. 306 p.

EISFELD, C. de L; BERGER, R. Análise das Estruturas de Mercado das Indústrias de Painéis de Madeira (Compensado, MDF e OSB) no Estado do Paraná. Floresta, Curitiba, v. 42, n. 1, p. 21-34, Janeiro-Março 2012.

FILHO, P. J. M; MOURA, A. C; BRITES, M.; LORENZONI, R. K; SCHAEFER, R. O. Concentração e Centralização do Capital na Indústria de Lacticínios Brasileira (2000-2001). Revista de Administração e Negócios da Amazônia. Rondônia, v.5, n.3, set/dez. 2013

FOOD AND AGRICULTURE ORGANIZATION OF THE UNITED NATIONS - FAO. Forestry Production and Trade. Disponível em <http://faostat3.fao.org/download/ F/FO/E > Acesso em: 28 de abril de 2015

GITMAN, L. J. Princípios de administração financeira. 12. ed. São Paulo: Pearson, 2010. 800 p.

GREGORY, G. R. Resource economics for foresters. New York: John Wiley \& Sons, 1987. 477 p.

KUPFER, D. HASENCLEVER, L. Economia Industrial: Fundamentos teóricos e práticas no Brasil. 2 ed. Rio de Janeiro: Elsevier, 2013. 382 p.

MELO, E. S.; TAVARES, J. M. Índices de concentração industrial em Minas Gerais: Uma análise sectorial (20052007). Reuna. v. 14, n. 1, p. 11-27, 2009.

SANTOS, R. B. do N. dos; SANTANA, A. C. de. Comportamento Recente do Setor Florestal Madeireiro no Estado do Pará, Brasil. R. Árvore, Viçosa-MG, v.33, n.3, p.533-543, 2009.

SILVA, Márcio Lopes da; SILVA, Rodrigo Firmino da. Aplicação da programação dinâmica na substituição de povoamentos florestais. Rev. Árvore, Viçosa , v. 31, n. 6, p. 1063-1072, Dec. 2007.

SOUZA, N. D. de; LIMA, H. S; CARVALHO, A. M; NASCIMENTO, A. M. do; JÚNIOR, A. F. D. Avaliação da qualidade de portas de madeira maciça por meio de cartas de controle. Ci. Madeira. Pelotas, v. 5, n. 2, p. 85-92, Outubro-Novembro 2014. 